Eos, Vol. 93, No. 42, 16 October 2012

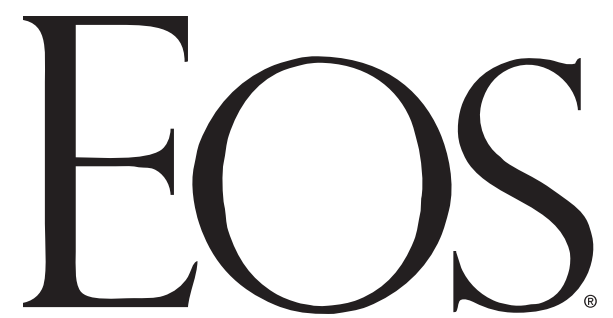

VOLUME 93 NUMBER 42

16 OCTOBER 2012

\title{
Leaking Methane Reservoirs Offshore Svalbard
}

\section{PAGES 413-414}

Methane hydrate-a solid substance in which methane is trapped within ice-like crystals-is stable at low temperatures and high pressures and may be destabilized by ocean warming on both geological and human time scales. Methane is a powerful greenhouse gas, and methane released from hydrate provides a potential positive feedback mechanism in global climate change [e.g., Archer and Buffett, 2005]-in theory, the more methane is released by the hydrates, the warmer the climate gets, causing the ocean to warm and release more methane. However, methane escaping from the seabed is oxidized and dissolved in the ocean, and insufficient methane may reach the atmosphere to affect the climate significantly. Its importance for climate change therefore depends on whether the flux from the seabed is great enough to overcome solution in the ocean and perturb atmospheric concentrations over sufficiently long time scales.

Methane hydrate has long been inferred from geophysical data to be present on the west Svalbard margin and in 2008 was directly sampled at the seabed [Fisher et al., 2011]. Also in 2008, more than 250 plumes of bubbles were discovered emanating from the seabed west of the Arctic archipelago of Svalbard by using a sonar system [Westbrook et al., 2009]. Samples of the plumes showed that the gas was methane, although there was no evidence for significant transport of methane into the atmosphere. The bubble plumes themselves mostly lie in a region that prior to 1980 was considered to have pressure and temperature conditions in which methane hydrates are stable at the seabed, but studies have shown that the hydrate stability field has receded over the past $3 \mathrm{dec}-$ ades because of warming of the west Spitzbergen current [Westbrook et al., 2009]. Some plumes even occur in deeper water, at depths where pressure and temperature conditions should keep the hydrates solidthese plumes emanate from pockmark features hundreds of meters in diameter on the seafloor. Moreover, geophysical data collected in 2008 and 2009 indicate that gas is widespread in pore space beneath the seabed [Rajan et al., 2012; Sarkar et al., 2012].

Since these discoveries, much international attention has been focused on the west Svalbard margin, with several research cruises scheduled each summer, primarily involving German, Norwegian, and U.K. vessels. To assess the likely future evolution of the methane flux into the ocean and from the ocean into atmosphere, researchers need to know the volume of methane (both as hydrates and as gas) stored beneath the seabed and the pathways by which it can reach the seafloor.

In August-September 2011 and July 2012 a research program using both seismic and electromagnetic techniques was conducted to determine these parameters. The program focused on two areas: (1) the region close to 400 meters below sea level along the continental slope that likely experienced hydrate dissociation when hydrate stability retreated to deeper depths (Figure 1a) and (2) a large pockmark at 1200 meters below sea level on the Vestnesa Ridge (Figure 1b), where bubble plumes are present, hydrate has been sampled at the seafloor, and geophysical data indicate the presence of hydrate beneath the seafloor.

\section{Specifics of Data Collection in 2011 and 2012}

Seismic and electromagnetic studies help to determine the amount of methane present below the seafloor: The presence of hydrate increases the seismic velocity and electrical resistivity of sediments beneath the seafloor, while the presence of gas pockets reduces the seismic velocity but increases the resistivity.

During both cruises, high-resolution multichannel seismic data were collected using a generator-injector (GI) air gun with 45-cubic-inch generator and injector chambers fired every 5 seconds and a 60-channel, 60-meter hydrophone streamer. This system provides subsurface images in the 30-250 hertz frequency range, with a dominant vertical resolution of 1.5 meters. During the 2011 cruise the deep-towed swept-frequency "chirp" source from the French Research Institute for Exploration of the Sea (Ifremer) was used for higher-resolution imaging of roughly the uppermost 200 meters beneath the seabed. On the continental slope a 2201050 hertz sweep was used, and on Vestnesa Ridge both this sweep and a 580-2200 hertz sweep were used. A shipboard subbottom profiler operating at 1-5 kilohertz provided higher-resolution images. Together these systems provided acoustic images of the subsurface across the frequency band 30-5000 hertz. To determine seismic velocities for depth conversion of acoustic images and to provide estimates of hydrate content, data from both types of source were recorded on ocean bottom seismometers (OBSs) equipped with a hydrophone and three orthogonal geophones at 4 kilohertz sample rates.

To determine the electrical resistivity of the subsurface both within and beneath the hydrate stability field, a frequency domain controlled source electromagnetic (CSEM) survey was collected using a transmitter towed 50 meters above the seafloor and emitting a 1 hertz square wave along a 100-meter antenna at 100 amperes. This signal was recorded by up to 14 ocean bottom electric field (OBE) receivers consisting of two horizontal and orthogonal 12-meter dipoles using silver-silver chloride electrodes and by a three-component electric field receiver towed 300 meters behind the antenna. Collection of fixed offset electric field data allows researchers to create a resistivity image of the top 100 meters of sediment at higher spatial resolution than usually attained on surveys because higherfrequency harmonics can be continuously sampled. These data will complement the seafloor electric field data. Because the CSEM profiles are coincident with both seismic and chirp data, a joint analysis will be possible. Both OBS and OBE instruments were placed on the seabed precisely at their planned sites using a small remotely operated vehicle, which also provided video images of the deployment sites.

\section{Preliminary Results}

High-resolution and chirp seismic reflection data show evidence for the widespread presence of subsurface gas at the slope site, both within and beneath the region of hydrate stability field recession. Here numerous subvertical fractures provide conduits for gas transport to the ocean floor. At the 
Eos, Vol. 93, No. 42, 16 October 2012

pockmark site, strong scattering in chirp images suggests the presence of pockets of gas within the hydrate stability field, and local increases in seismic velocity within the hydrate stability field provide evidence for a concentration of hydrate beneath the pockmark. The combined data set will provide better estimates of the volume of hydrate and gas in the subsurface, constrain the mechanisms by which gas escapes, and complement the work of other groups studying its transport from the seabed through the water column into the atmosphere.

\section{Acknowledgments}

Work at sea was funded by the U.K. Natural Environment Research Council and Ifremer. We thank all who sailed with us on cruises JR269A and JR269B for their contributions to the success of both cruises.

\section{References}

Archer, D., and B. Buffett (2005), Time-dependent response of the global ocean clathrate reservoir to climatic and anthropogenic forcing, $\mathrm{Geo}$ chem. Geophys. Geosyst., 6, Q03002, doi:10.1029/ 2004GC000854.

Fisher, R. E., et al. (2011), Arctic methane sources: isotopic evidence for atmospheric inputs, Geophys. Res. Lett., 38, L21803, doi:10.1029/ 2011GL049319.

Rajan, A., J. Mienert, and S. Bünz (2012), Acoustic evidence for a gas migration and release system in Arctic glaciated continental margins offshore NW-Svalbard, Mar. Pet. Geol., 32, 36-49, doi:10.1016/j.marpetgeo.2011.12.008.

Sarkar, S., C. Berndt, T. A. Minshull, G. K. Westbrook, D. Klaeschen, D. G. Masson, A. Chabert, and K. Thatcher (2012), Seismic evidence for

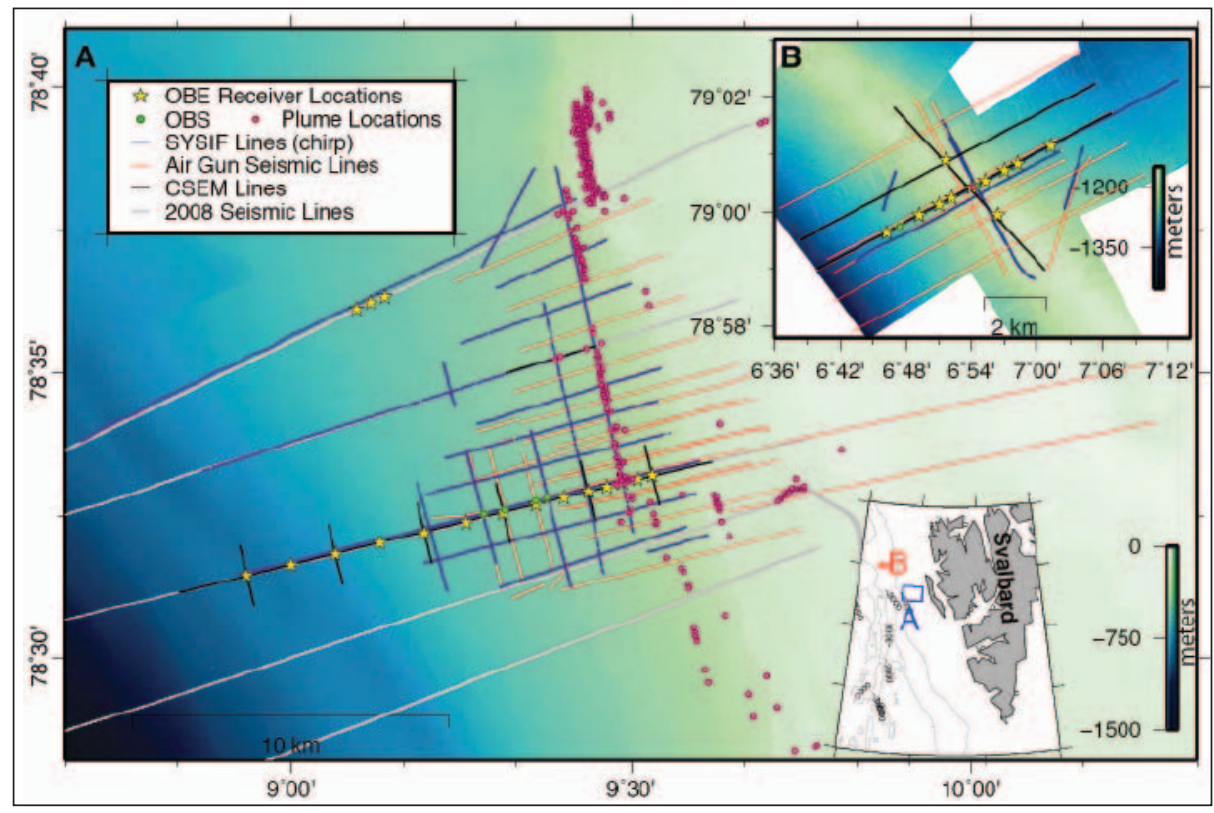

Fig. 1. Bathymetry of the west Svalbard margin with tracks for air gun seismic lines, the deeptowed swept-frequency "chirp" source (SYSIF) lines, and controlled source electromagnetic (CSEM) lines as well as seabed ocean bottom electric field (OBE) and ocean bottom seismometer (OBS) receiver locations. Also displayed are gas plume locations [Westbrook et al., 2009] and seismic lines [Sarkar et al., 2012] from the region's 2008 survey. Survey regions A and B can be seen in the inset map.

shallow fluid-escape features off shore west Svalbard, J. Geophys. Res., 117, B09102, doi:10.1029/ 2011JB009126.

Westbrook, G. K., et al. (2009), Escape of methane gas from the seabed along the West Spitsbergen continental margin, Geophys. Res. Lett., 36, L15608, doi:10.1029/2009GL039191.

-T. A. MinshulL, National Oceanography Centre Southampton, University of Southampton, Southampton,UK; E-mail: tmin@noc.soton.ac .uk; G. K.WESTBROOK, National Oceanography Centre Southampton, University of Southampton, Southampton, UK; also at Ifremer Centre de Brest, Plouzane, France; K. A. WeitemEYER, M. C. SinHA, and B. K. GoswAmi, National Oceanography Centre Southampton, University of Southampton, Southampton, UK; and B. MARSSET, Ifremer Centre de Brest, Plouzane, France 